\title{
Comparison of Various Techniques of Anesthesia for Surgical Management of Diabetic Foot
}

\author{
Kapil S. Divekar ${ }^{\oplus 1}$, Karishma D. Mehta ${ }^{2}$, Pancham Mehta ${ }^{\circledR 3}$, Payal P. Prajapati ${ }^{\odot 4}$, Kamla H. Mehta ${ }^{\circ} 5$ \\ ${ }^{1}$ Ex-resident, Department of Anesthesiology, Smt. SCL General Hospital, Smt. NHL Municipal Medical College, Ahmedabad, Gujarat, India, ${ }^{22}$ nd year Resident, \\ Department of Anesthesiology, Smt. SCL General Hospital, Smt. NHL Municipal Medical College, Ahmedabad, Gujarat, India, ${ }^{3}$ Senior Resident, Department of \\ Anesthesiology, AMC MET Medical College, Ahmedabad, Gujarat. Fax: India, ${ }^{4} 1$ st year Resident, Department of Anesthesiology, Smt. SCL General Hospital, Smt. NHL \\ Municipal Medical College, Ahmedabad, Gujarat, India, ${ }^{5}$ Professor, Department of Anesthesiology, Smt. SCL General Hospital, Smt. NHL Municipal Medical College, \\ Ahmedabad, Gujarat, India.
}

\section{Abstract}

Background: Diabetes mellitus is a multisystem disease caused by an absolute or relative deficiency of insulin secretion or resistance or a combination of both. Anesthesia in them is of special concern because of complex polypharmacy, an inappropriate dose of oral hypoglycemic agents or insulin and errors in converting IV insulin to usual medication. The objective is to compare the various techniques of anesthesia for surgical management of diabetic foot in terms of intraoperative hemodynamic stability, perioperative problems related to anesthesia techniques, postoperative analgesia. Subjects and Methods: Sixty adult diabetic patients of both gender of ASA grade II-III, aged $\geq 35 y e a r s$ undergoing surgical management of diabetic foot were elected and separated into three groups, Group A: general anesthesia with tracheal intubation, Group B: unilateral spinal anesthesia with injection $0.5 \%$ bupivacaine heavy $1.5 \mathrm{ml}(7.5 \mathrm{mg})$, Group C: popliteal nerve block via lateral approach by injecting $30 \mathrm{ml} \mathrm{0.5 \%}$ bupivacaine. Parameters like pulse rate, mean arterial blood pressure, respiratory rate and $\mathrm{SpO}_{2}$ were recorded at regular intervals. Postoperative pain, perioperative side effects, complications and problems related to anesthetic techniques were noted. The analysis is done by unpaired t-test and chi-square test. Results: Group C patients were hemodynamic stable than Group A and B. Post-op analgesia was prolonged in Group C. Perioperative side effects were more found in Group A. Conclusion: Popliteal nerve block and unilateral spinal anesthesia provide better hemodynamic stability and postoperative analgesia with negligible side effects as compared to general anesthesia for surgical management of diabetic foot.

Keywords: Diabetic foot, general anesthesia, unilateral spinal anesthesia, popliteal nerve block

Corresponding Author: Kamla H. Mehta, Professor, Department of Anesthesiology, Smt. SCL General Hospital, Smt. NHL Municipal Medical College, Ahmedabad, Gujarat, India.

E-mail: drkhmeht12a@gmail.com

Received: 02 September $2020 \quad$ Revised: 11 October $2020 \quad$ Accepted: 19 October 2020 Published: 16 December 2020

\section{Introduction:}

Diabetes mellitus is a multisystem involving disease caused by an absolute or relative deficiency of insulin secretion or insulin resistance or a combination of both. ${ }^{[1,2]}$ Anesthesia in diabetic patients is a special concern because of the following reasons like complex polypharmacy and an inappropriate dose of oral hypoglycemic agents, insulin and errors in converting IV insulin to usual medication.

Surgical involvement may be needed to direct diabetic foot infections from minor to major interventions, such as debridement or amputation. ${ }^{[3,4]}$ Threat of lower extremity amputation amid patients with diabetes may be as elevated as $70 \%$, and the most common reason for non-traumatic LEA is a diabetic foot ulcer. ${ }^{[5-7]}$

Surgery for the diabetic foot is a comparatively small operation with insignificant blood loss, but given that anesthesia for these patients is a common confront since of serious comorbidities. Complications of diabetes may alter the outcome of the surgery. Hence, anesthesiologists should be attentive concerning treating these simultaneous conditions to make sure optimal perioperative management of diabetic patients. ${ }^{[8]}$ The peripheral site of the surgical place in the foot and ankle surgery and the likelihood to chunk the pain pathways at numerous levels present a clear benefit of regional anesthesia in this location. ${ }^{[8,9]}$ The popliteal nerve block is quite suitable for diabetic foot surgeries. 
This technique does not affect the treatment of the systemic diseases of these patients. ${ }^{[10,11]}$ Lateral approach of popliteal nerve block offers adequate anesthesia and postoperative analgesia for foot and ankle surgery. ${ }^{[10,12,13]}$

Zeinab I, Hossary, Hala A. Attar, OlfatA.I, Amin, Sherif Mowafy had compared the spinal anesthesia against the lateral approach of popliteal nerve block for diabetic foot surgeries. ${ }^{[14]}$ NaYoung et al compared the things of general anesthesia and popliteal nerve block on postoperative pain and hemodynamic stability in diabetic patients undergoing distal foot amputation. ${ }^{[15]}$

Research studies regarding comparisons of three methods of anesthesia, such as general anesthesia, unilateral spinal anesthesia and popliteal nerve block were not found. Therefore the present study was conducted to compare all these three techniques in terms of their hemodynamic stability and postoperative analgesic effects for the surgical management of diabetic foot.

\section{Aims and Objectives:}

The present study of 60 patients was carried out to compare various techniques of anesthesia like general anesthesia, unilateral spinal anesthesia \& popliteal nerve block for surgical management of diabetic foot in terms of

1) Intraoperative hemodynamic stability.

2) Perioperative side effects \& complications.

3) Problems related to anesthetic techniques.

4) Postoperative analgesia.

\section{Inclusion Criteria:}

A total of 60 adult diabetic patients of both genders belonged to ASA grade II, III aged $\geq 35$ years undergoing surgical management of diabetic foot were selected.

\section{Exclusion Criteria:}

Patients having

1) History of diabetic ketoacidosis.

2) Blood sugar $\geq 250 \mathrm{mg} / \mathrm{dl}$.

3) Severe sepsis, coagulopathy, neurological disorders, psychiatric and muscular disorder.

4) Severe renal or hepatic impairment.

5) History of allergy to local anesthetics used.

\section{Subjects and Methods}

A total of 60 adult diabetic patients of both genders belonged to ASA grade II-III, aged $\geq 35$ years undergoing surgical management of diabetic foot were selected. After taking written informed consent, patients were divided into three groups,
Group A: patient received general anesthesia with tracheal intubation.

Group B: patient received unilateral spinal anesthesia with an injection of $0.5 \%$ bupivacaine heavy $1.5 \mathrm{ml}(7.5 \mathrm{mg})$.

Group C: patient received popliteal nerve block via lateral approach by injecting $30 \mathrm{ml} 0.5 \%$ bupivacaine under ultrasound guidance and peripheral nerve stimulation assists.

The following parameters were recorded in each group: Baseline hemodynamic parameters like pulse rate, mean arterial blood pressure, respiratory rate and $\mathrm{SpO}_{2}$ were noted at regular intervals. The duration of analgesia was also noted. The postoperative pain intensity was evaluated by a visual analog scale (VAS) immediately postoperative and then at 2, 4, 8 and 12 hours postoperative. Perioperative side effects and complications such as hypoglycemia, hyperglycemia, bradycardia, tachycardia, hypotension, hypertension, nausea, vomiting, respiratory depression and urinary retention were recorded. Problems related to anesthetic techniques such as difficult mask ventilation and difficult intubation for general anesthesia, block formation time(BFT), time being ready for operation(TBRFO), first analgesic need time(FANT) were noted for each group. Data were expressed as mean \pm SD or numbers and percentages. Analysis of data was done by using unpaired t-test and chi-square test. Medcalc software version 10.6.1.0.was used. The $p$-value of $<0.05$ was measured as statistically significant.

Results:

\section{Hemodynamic changes:}

The baseline pulse rate and the map was comparable in all three groups. But pulse rate was superior in Group A as compared to Group B and Group C at 5 min (p-value $<0.0001$ ) intubation time, $45 \min (\mathrm{p}$ value $=0.0011)$ and $60 \mathrm{~min}(\mathrm{p}$-value $<0.0001)$ during extubation period which was highly significant. Mean arterial blood pressure was higher in Group A as compared to Group B and Group C patients at $45 \mathrm{~min}$ ( $\mathrm{p}$ value $=0.0002$ ) and 60 min ( $\mathrm{p}$ value $=0.0002$ ) during the extubation period which was highly significant.

\section{Duration of analgesia:}

The duration of analgesia was highest in Group C $(241.11 \pm 25.76 \mathrm{~min})$. It was highly significant (p-value $<0.0001)$.

\section{Postoperative Visual Analogue Scale:}

Postoperative VAS was higher in Group A $(3.41 \pm 1.18 \mathrm{~cm})$ at 2 hours, while it was $(3.51 \pm 1.05 \mathrm{~cm})$ for Group B and $(3.61 \pm 1.09 \mathrm{~cm})$ for Group $\mathrm{C}$ at 4 hours which was highly significant. (p-value $<0.0001$ ).

\section{Perioperative side effects and complications:}


Table 1: Demographic Data:

\begin{tabular}{llll|}
\hline Parameters & Group A & Group B & Group C \\
\hline Age(yr.) & $53.41 \pm 13.48$ & $50.85 \pm 14.32$ & $59.75 \pm 10.55$ \\
\hline Weight(kg) & $64.11 \pm 18.4$ & $60.25 \pm 14.7$ & $61.21 \pm 11.1$ \\
\hline Height(cm) & $162.25 \pm 6.21$ & $162.25 \pm 5.33$ & $163.21 \pm 6.67$ \\
Sex(M:F) & $10: 10$ & $15: 5$ & $13: 7$ \\
\hline ASA grade II: III & $4: 16$ & $3: 17$ & $2: 18$ \\
Elective:Emergency & $8: 12$ & $9: 11$ & $7: 13$ \\
\hline
\end{tabular}

There were more hyperglycemia, hypertension and tachycardia in Group A as compared to Group B and Group c.

\section{Problems related to anesthesia technique:}

Difficult mask ventilation was found $5 \%$ and difficult intubation was found $10 \%$ in Group A patients.Block formation time was higher in Group C as compared to Group B patients, which was highly significant. The first analgesic need time was highly significant between all three groups. The total number of rescue analgesic dose was higher in Group A as compared to Group B and Group C patients.

\section{Discussion}

The diabetic patients provide several challenges to the anesthesiologist, most of which can be predicted with good preoperative evaluation, careful monitoring and understanding of the relevant pathophysiological features. Premature involvement sequentially to avoid and treat possible disaster in the management of diabetic foot is not only immense accountability, except as well a huge occasion.

The present studies were carried out to appraisal and evaluate anesthetic modalities with deference to hemodynamic stability and postoperative analgesia in patients for the surgical management of diabetic foot given general anesthesia versus unilateral anesthesia versus popliteal nerve block. The increases in circulating glucose, epinephrine and cortisol concentrations as a result of the stress response to surgery under general anesthesia are blocked by unilateral spinal anesthesia and popliteal nerve block. A further advantage of regional techniques comprises a stirring patient who can report hypoglycemic symptoms together with the common advantage of outstanding analgesia and fewer nausea, vomiting and permitting the previous recommencement of oral intake. In the present study, the hemodynamic parameters were constant and less fluctuant throughout the intraoperative period in Group B \& Group C as compared to Group A patients. Effective pain management is necessary for optimal care of patients in the postoperative period. In our study, popliteal nerve block and unilateral spinal anesthesia provided excellent results of postoperative pain control.
Difficult mask ventilation was found $5 \%$ and difficult intubationwasfound $10 \%$ in Group A patient block formation time was higher in Group C $(8.95 \pm 0.82 \mathrm{~min})$ as compared to Group B $(5.35 \pm 0.67 \mathrm{~min})$ patients (p value $<0.0001)$. For a long time diabetic patients airway manifests with joint rigidity. Abnormal cross-linking of collagen in joints and other tissues. In this study, a larger duration for performing the block was observed in the popliteal block group relative to the unilateral spinal anesthesia group. This is in accordance with Jeon HJ et al, who conducted a study comparing clinical properties and patient satisfaction between spinal anesthesia and popliteal nerve block for the hallux valgus surgery and found that the time is taken for the nerve block in the popliteal group was longer than that taken for the spinal anesthesia group. ${ }^{[2,3]}$ Duration of analgesia: When unilateral spinal anesthesia is planned, limiting the block to lesser dermatomal level sand evading the incidence of hypotension is significant since fluid loading and vasopressor management might not be perfect techniques to manage hypotension as end-stage renal disease and coronary artery occlusive diseases are widespread in diabetic patients. Single-shot unilateral spinal anesthesia can be utilized for such operative procedures. The popliteal nerve block is quite suitable for diabetic foot surgeries. This technique does not affect the treatment of the systemic diseases of these patients. A lateral approach to the sciatic nerve through the popliteal fossa provides adequate anesthesia and postoperative analgesia for foot and ankle surgeries. Our research established that, although performing popliteal nerve block obtained somewhat larger time than unilateral spinal anesthesia and time necessary to attain surgical anesthesia was longer in popliteal nerve block and unilateral spinal anesthesia compared to general anesthesia, popliteal nerve block and unilateral spinal anesthesia resulted in less side effects and complications and better outcome as compared to general anesthesia in diabetic patients undertake foot surgery.

Our findings are consistent with findings of $\mathrm{Na}$ Young Kim and others (2016) ${ }^{[15]}$ ZeinabI and others (2015) conducted that popliteal nerve block provided more stable hemodynamic data than unilateral spinal anesthesia in elderly patients. 


\section{Conclusion}

Popliteal nerve block and unilateral spinal anesthesia provide better analgesia with minimal side effects as compared to general anesthesia for surgical management of diabetic foot.

\section{References}

1. Association AD. Diagnosis and Classification of Diabetes Mellitus. Diabetes Care. 2009;32(Suppl 1):S62-S67. Available from: https://dx.doi.org/10.2337/dc09-S062.

2. Association AD. Diagnosis and classification of diabetes mellitus. Diabetes Care .2011;34(Suppl 1):S62-S69. Available from: https://dx.doi.org/10.2337/dc11-S062.

3. Weledji EP, Fokam P. Treatment of the diabetic foot - to amputate or not? BMC Surg. 2014;14:83. Available from: https://dx.doi.org/10.1186/1471-2482-14-83.

4. Choi MSS, Jeon SB, Lee JH. Predictive factors for successful limb salvage surgery in diabetic foot patients. BMC Surg. 2014;14:113. Available from: https://doi.org/10.1186/14712482-14-113.

5. Bruun C, Siersma V, Guassora AD, Holstein P, de Fine Olivarius N. Amputations and foot ulcers in patients newly diagnosed with Type 2 diabetes mellitus and observed for 19 years. The role of age, gender and co-morbidity. Diabet Med. 2013;30(8):964-972. Available from: https://doi.org/10.1111/ dme.12196.

6. Nerone VS, Springer KD, Woodruff DM, Atway SA. Reamputation after Minor Foot Amputation in Diabetic Patients: Risk Factors Leading to Limb Loss. J Foot Ankle Surg. 2013;52(2):184-187. Available from: https://doi.org/10.1053/ j.jfas.2012.11.015.

7. Frykberg RG, Zgonis T, Armstrong DG, Driver VR, Giurini JM, Kravitz SR, et al. Diabetic Foot Disorders: A Clinical Practice Guideline (2006 Revision). J Foot Ankle Surg . 2006;45(5):1-66. Available from: https://doi.org/10.1016/ s1067-2516(07)60001-5.

8. Kim SH, Cho MJ, Shiny S, Lee JS, Leej W, Yoon KB. Spinal anesthesia with $3.75 \mathrm{mg}$ of $0.25 \%$ hyperbaric bupivacaine for diabetic foot surgery. Korean J Anesthesiol. 2009;56(3):273279.

9. Singh RA, Juma A, Haifi TH, Nour MB, A. Amputation of Lower Extremity in Diabetic and High-Risk Patients under
Peripheral Nerve Blocks(CombinedSciaticand3-in-1Femoral Blocks). Kuwait Med J . 2001;33:310-316.

10. Deschner B, Robards C, Xu D, Soma-Sundaram L, Hadzic A. A comprehensive review of lower extremity peripheral nerve blocks. J NYSORA. 2009;12:11-22.

11. Amin WA, O ASM, F SM, F MS, M AHT, A SE. Continuous Sciatic Nerve Block: Comparative study between the parsacral, lateral, and anterior approaches for lower limb surgery. J Anesth. 2010;20(5):695-702.

12. Palaniappan T, Vani S, Ravikumar S, Mohan V. Comparison of lateral versus posterior approach of popliteal nerve block for diabeticfootsurgeries. Indian J Anaesth. 2006;50(4):262-265.

13. McCartney CJL, Brauner I, Chan VWS. Ultrasound guidance for a lateral approach to the sciatic nerve in the popliteal fossa. Anaesthesia. 2004;59(10):1023-1025. Available from: https: //dx.doi.org/10.1111/j.1365-2044.2004.03872.x.

14. Hossary ZIE, Attar HAE, Amin O, Mowafy SMS. A Comparison of Spinal Anesthesia Versus Lateral Approach of Popliteal Nerve Block for Diabetic Foot Surgeries. Med J Cairo Univ. 2015;83:463-472.

15. Kim NY, Lee KY, Bai SJ, Hong JH, Lee J, Park JM, et al. Comparison of the effects of remifentanil-based general anesthesia and popliteal nerve block on postoperative pain and hemodynamic stability in diabetic patients undergoing distal foot amputation. Medicine. 2016;95:e4302-e4302. Available from: https://dx.doi.org/10.1097/md.0000000000004302.

Copyright: (C) the author(s), 2020. It is an open-access article distributed under the terms of the Creative Commons Attribution License (CC BY 4.0), which permits authors to retain ownership of the copyright for their content, and allow anyone to download, reuse, reprint, modify, distribute and/or copy the content as long as the original authors and source are cited.

How to cite this article: Divekar $\mathrm{KS}$, Mehta $\mathrm{KD}$, Mehta $\mathrm{P}$, Prajapati PP, Mehta KH. Comparison of Various Techniques of Anesthesia for Surgical Management of Diabetic Foot. Acad. Anesthesiol. Int. 2020;5(2):62-65.

DOI: dx.doi.org/10.21276/aan.2020.5.2.13

Source of Support: Nil, Conflict of Interest: None declared. 